\title{
Spiral stent placement for bile leakage after hepatobiliary surgery
}

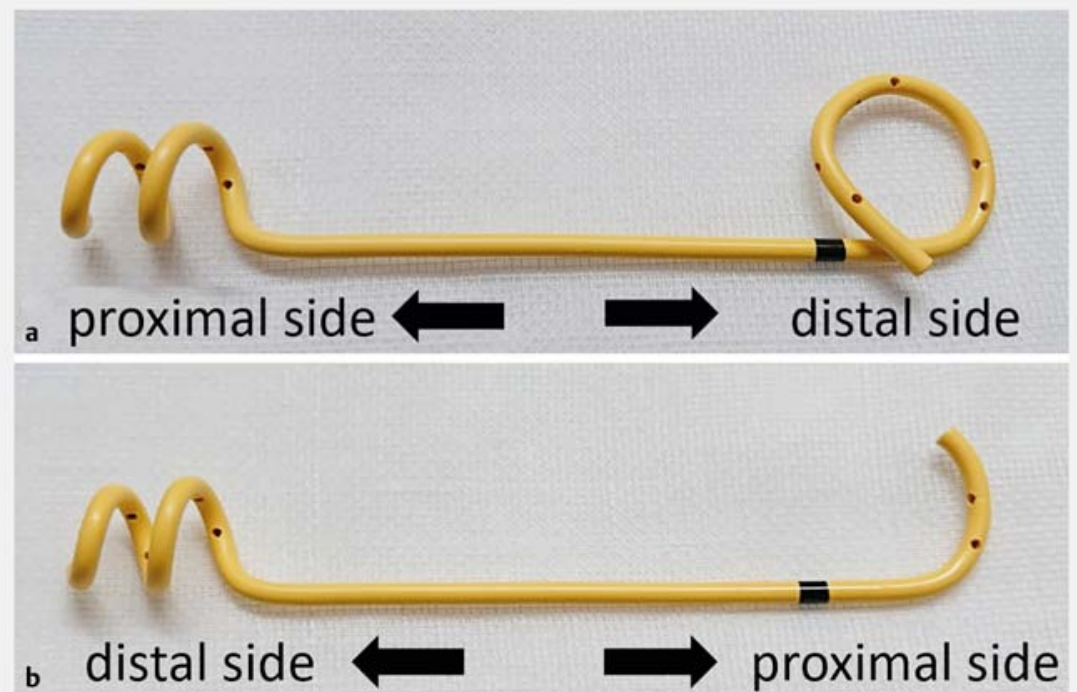

Fig. 1 Spiral-K (Gadelius Medical K.K., Tokyo, Japan). a Originally, the spiral end was placed proximally and the pigtail end was placed distally. $\mathbf{b}$ We shortened the pigtail end of the stent and placed the stent upside down such that the spiral end was positioned distally.
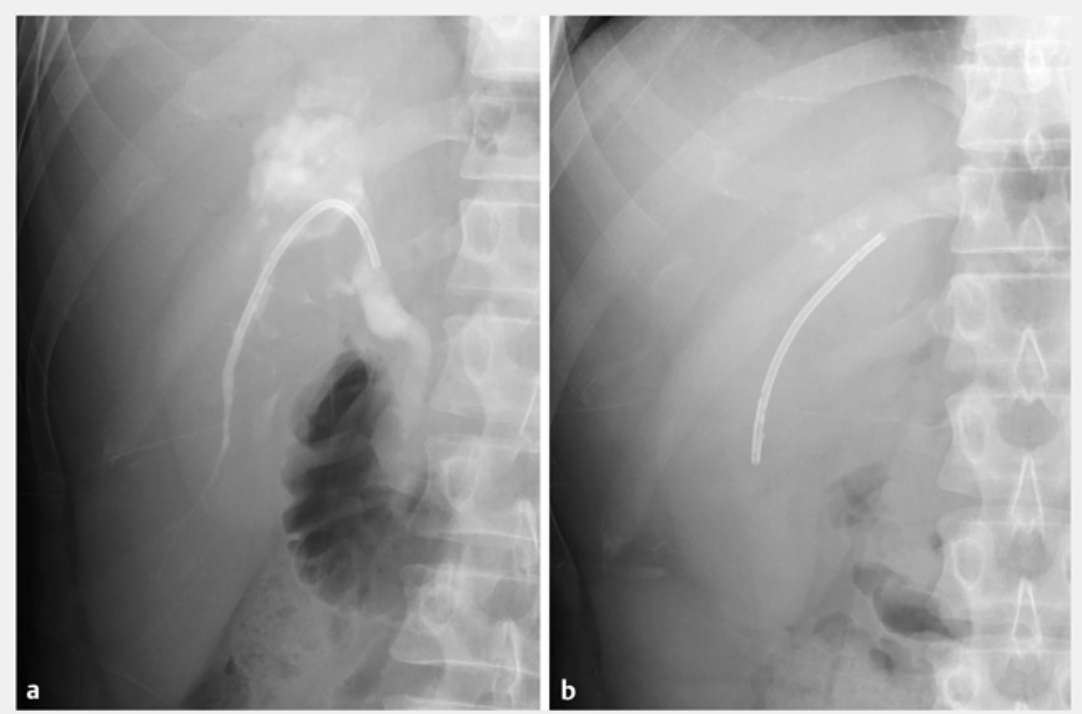

- Fig. 3 An internal stent $(7 \mathrm{Fr}, 9 \mathrm{~cm}$ ) was placed but migrated deep into the proximal duct. a Immediately after stent placement; $\mathbf{b} 3$ months later.

Endoscopic drainage, especially endoscopic nasobiliary drainage (ENBD) followed by stent placement, is recom- mended for bile leakage after hepatobiliary surgery [1-3]. However, these stents can sometimes migrate, depending on

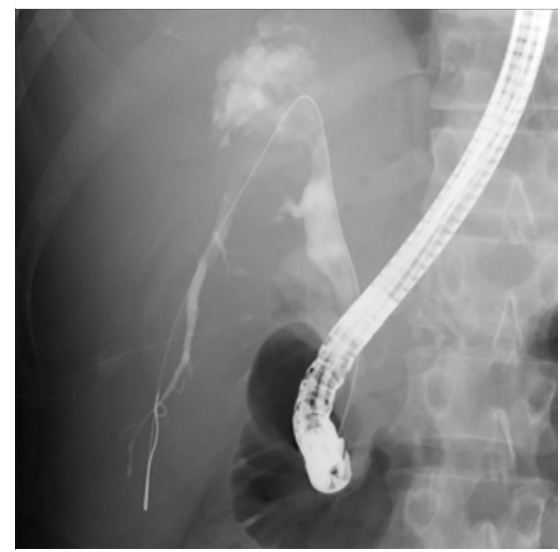

- Fig. 2 Endoscopic retrograde cholangiography revealed a stricture and bile leakage at the hepatic hilum.

the ability of the stent to conform to the bile duct postoperatively. To solve this problem, we used a unique plastic stent (Spiral-K, Gadelius Medical K.K., Tokyo, Japan) ( $>$ Fig. 1 a) placed above the papilla. Originally, the spiral end was placed proximally and the pigtail end was placed distally. We shortened the pigtail end and placed the stent upside down such that the spiral end was positioned distally ( Fig. 1 b).

A 35-year-old man was referred to our hospital for bile leakage after a left hepatic lobectomy performed for alveolar echinococcosis. Endoscopic retrograde cholangiography revealed a stricture and bile leakage at the hepatic hilum ( Fig.2). Initially, we placed an ENBD tube (6 Fr) across the stricture; however, the tube was dislocated immediately. Next, we placed a fully covered, intraductal, self-expanding, metal stent $(10 \times$ $70 \mathrm{~mm}$ ); however, the stent had migrated distally 1 month later. At the third treatment attempt, we placed an internal stent $(7 \mathrm{Fr}, 9 \mathrm{~cm})$ with a distal thread; however, 3 months later, this stent had also migrated deep into the proximal duct ( $\triangleright$ Fig.3), making removal difficult. Finally, the Spiral-K stent $(7 \mathrm{Fr}, 20 \mathrm{~cm}$ ) was placed above the papilla upside 


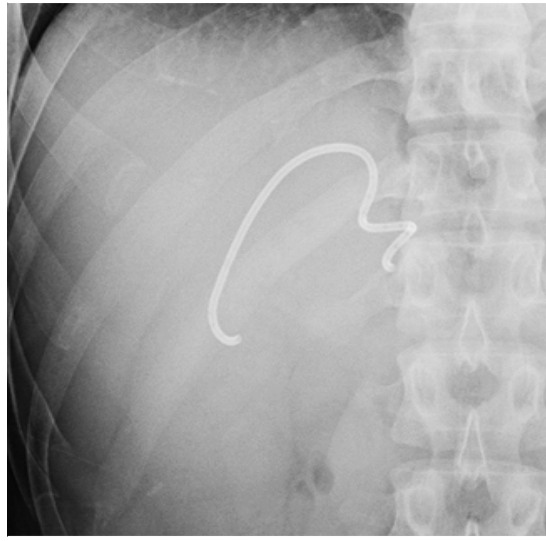

-Fig. 4 The spiral stent placed above the papilla in an upside-down manner.

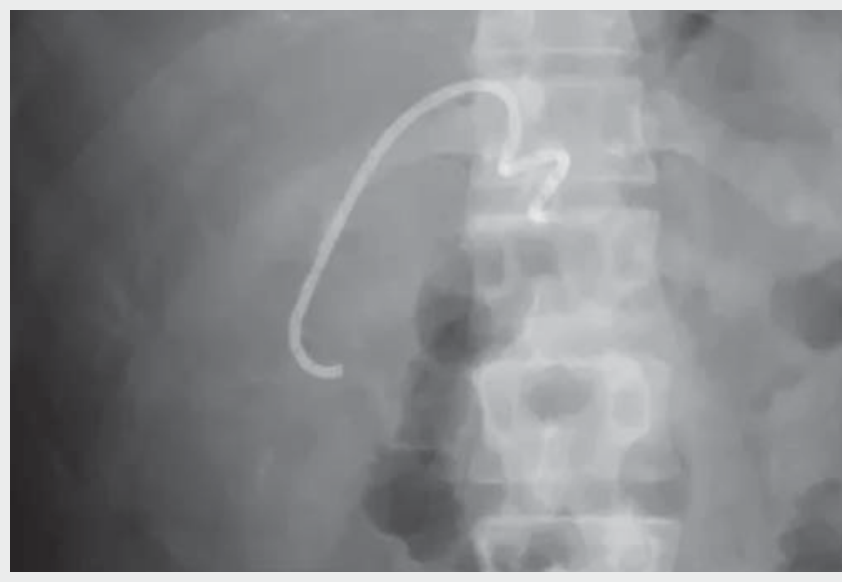

$\checkmark$ Video 1 Spiral stent placement for bile leakage after hepatobiliary surgery.

\section{Corresponding author}

- Video 1), to prevent stent migration and allow easy stent exchange. No stent migration had occurred 8 months after placement. The Spiral-K stent was easily removed using grasping forceps and replaced with another stent of the same type.

This is the first report of a suprapapillary spiral stent placed in an upside-down fashion. The distally placed spiral end works as an anchor, preventing migration and allowing easy removal.

Endoscopy_UCTN_Code_CCL_1AZ_2AZ

\section{Competing interests}

The authors declare that they have no conflict of interest.

\section{The authors}

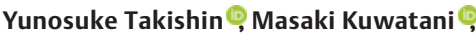 Naoya Sakamoto}

Department of Gastroenterology and Hepatology, Hokkaido University Hospital, Sapporo, Japan

\section{Masaki Kuwatani, MD}

Department of Gastroenterology and Hepatology, Hokkaido University Hospital, North 14, West 5, Kita-ku, Sapporo 0608648, Japan

mkuwatan@med.hokudai.ac.jp

\section{References}

[1] Yabe S, Kato H, Mizukawa S et al. Predictive factors for outcomes of patients undergoing endoscopic therapy for bile leak after hepatobiliary surgery. Dig Endosc 2016; 29: $353-$ 361

[2] Mutignani M, Forti E, Dokas S et al. Endotherapy for bile leaks from isolated ducts after hepatic resection: a long awaited challenge. Dig Liver Dis 2017; 49: 893-897

[3] Kurita A, Kodama Y, Minami R et al. Endoscopic stent placement above the intact sphincter of Oddi for biliary strictures after living donor liver transplantation. J Gastroenterol 2013; 48: 1097-1104

\section{Bibliography}

Endoscopy 2022; 54: E174-E175

DOI 10.1055/a-1463-2776

ISSN 0013-726X

published online 28.4.2021

(c) 2021. Thieme. All rights reserved. Georg Thieme Verlag KG, Rüdigerstraße 14, 70469 Stuttgart, Germany

\section{ENDOSCOPY E-VIDEOS}

https://eref.thieme.de/e-videos

口古回 Endoscopy E-Videos is an open access online section, 自嗮: reporting on interesting cases and new techniques in gastroenterological endoscopy. All papers include a high quality video and all contributions are freely accessible online. Processing charges apply (currently EUR 375), discounts and wavers acc. to HINARI are available.

This section has its own submission website at https://mc.manuscriptcentral.com/e-videos 